\title{
Interpretation of the evolution of life and consciousness through the consciousness model
}

\author{
Dhananjay Pal \\ Email address: \\ dhananjay.pal123@gmail.com,paldhananjay46@yahoo.com
}

Pharmacy College, Bengal School of Technology, Sugandha-Delhi Road, Chuchura, Dist.-Hooghly, West Bengal, INDIA, PIN-712 102

\section{To cite this article:}

Dhananjay Pal. Interpretation of the Evolution of Life and Consciousness through the Consciousness Model. American Journal of Physics and Applications. Vol. 2, No. 1, 2014, pp. 6-18. doi: 10.11648/j.ajpa.20140201.12

\begin{abstract}
A single field emerged at the origin of the universe, already containing within itself the blueprint of the physical universe. The primordial single field triggered the onset of the universe. Most physicists believe that a single super-force dominated the first instants of creation. Scientists have arrived at a simple but decisive conclusion that consciousness is very much a part of the universe, like other objects. Our consciousness model involving thought-carrying particle (TCP), thought retaining particle (TRP) and thought force (TF) signifies the existence of universal consciousness that exists along with the universe. This universal consciousness is a functional state of the universal mind (UM). This UM is evolved at the Big Bang from void. The UM is constituted by these TCP and TRP in the inherent presence of thought force (TF). Thought force (TF) is an expression of universal consciousness. The Thought force (TF) being the primordial quantum field functions as the original super-force. TF being the original super-force functions as the origin of all the fundamental fields. TCP is the carrier of thought force (TF) that, in turn, appears to be the origin of all the fields. The quantized energy $\left(\varepsilon_{T}\right)$ of TCP is responsible to cause the universal consciousness as well as the cosmic microwave background radiation temperature. The individual consciousness owes its origin to the universal consciousness created by the same $\varepsilon_{T}$. The same $\varepsilon_{T}$ is the energy responsible for generating thought force (TF). TF being an expression of the universal consciousness is applicable to any inanimate object as well as to any biological system (having thinking ability). The TF exerts its functions both in vitro and in vivo. Any matter as well as any individual mind is constituted by these TCP and TRP in the inherent presence of thought force (TF) in vitro and thought force (TF) in vivo and these TCP and TRP are originated from the same eternal Void. The consciousness model may provide guidelines to interpret the evolution of universe, life and consciousness.
\end{abstract}

Keywords: Void, Universal Mind (UM), Thought Force (TF), Though-Carrying Particles (TCP), Thought Retaining Particles (TRP), Quantized Energy ( $\in$ T) of TCP, Universe Wide Web (UWW), Cosmic Microwave Background Radiation (CMBR)

\section{Introduction}

In Eastern philosophical traditions, consciousness is intrinsic to the universe, whereas in most Western views, consciousness is extrinsic, emerging from complex computation. How can these views be reconciled?

It is most relevant and important to indicate the names of various eminent physicists like Erwin Schrödinger, Eugene Wigner, Brian Josephson, John Wheeler, Roger Penrose, Henry P Stapp, Freeman J. Dyson, Paul Davies, David Bohm, Basil Hiley, Fritjof Capra, Fred Alan Wolf and Amit Goswami who have addressed the inclusion of consciousness in their work. Consciousness is to be taken into account.

1.1. In contrast to the usual linear sequence of matter, body, life, brain, mind, consciousness, here the proposed cyclic sequence is first universal consciousness (a functional state of the universal mind), and then matter, body, life, brain, and regeneration of mind and consciousness. The evolution of life with mind and consciousness is possible purely due to the inherent existence of universal consciousness which exists along with the universe. The human nervous system is evolved to provide an appropriate material structure to individualize the universal consciousness, a characteristic of reality, pervading all manifestations.

Consciousness model of Pal et al [1-3] involving TCP, TRP and thought force $\left(\mathrm{T}_{\mathrm{F}}\right)$ signifies the existence of universal consciousness that exists along with the universe. Pal et al [3] showed that this universal consciousness is a functional state of Universal Mind (UM). Pal et al [3] explained that the UM is evolved at the Big Bang from the eternal Void. This Void, in turn, is the source of infinite 
energy. And this UM is a finer matter. The individual mind being a constituent of the UM is also a finer matter. The constituents of the UM and individual mind are the same. The ultimate constituents of matter and mind are the same as both mind and matter are aspects of one fundamental reality, which is called UM. The brain is the mediating link or interface between the individual mind and body.

Pal et al [3] explained that the constituents of the UM are the ultimate constituents of matter itself as everything in this universe is a manifestation of this UM. Pal et al [3] expressed that the UM is constituted by these TCP and TRP in the inherent presence of thought force $\left(\mathrm{T}_{\mathrm{F}}\right)$. Pal et al $[1,3]$ further explained that the ultimate constituents of matter and mind are these TCP and TRP in the inherent presence of thought force $\left(\mathrm{T}_{\mathrm{F}}\right)$ in vitro and thought force $\left(\mathrm{T}_{\mathrm{F}}\right)$ in vivo [See Scheme-I].

\subsection{General View for the Evolution of the Universe}

Big Bang $\rightarrow$ Universe $\rightarrow$ [Fields + Particles \& Antiparticles + STC $] \rightarrow[$ Matter and Fields + STC $] \rightarrow$ Matter and Fields + STC + Life as well as consciousness.

Many physicists agree with the idea that consciousness is non-local and fundamental in the universe. Scientists have arrived at a simple but decisive conclusion that consciousness is very much a part of the universe, like other objects. As per Roger Penrose, consciousness is a part of the universe. If the universe exists along with the universal consciousness that, in turn, is a functional state of the universal mind (UM) and if this $\mathrm{UM}$ is evolved at the Big Bang from the eternal void, then I):

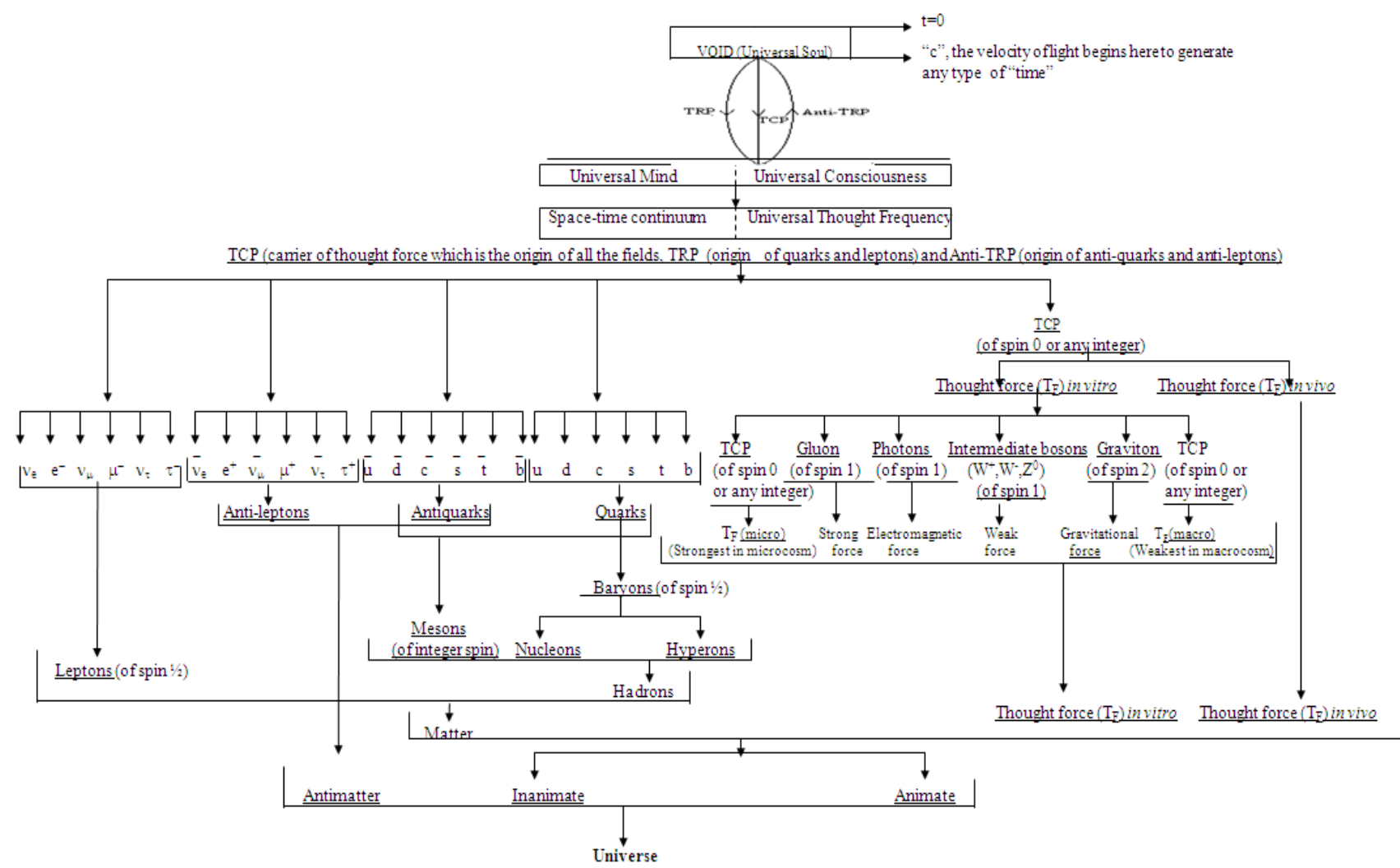

Scheme-I: Schematic presentation showing the evolution of the universe from the Void incorporating the postulated TCP (Thought-carrying particle), TRP (Thought-retaining particle) and Thought Force $\left(T_{F}\right)$. Laws of absolute conservation of mass, charge (and color) are to be maintained in order to develop a general theory for the unification of physics which would be freely applicable to the more general situations involving both the non-living system and living system having consciousness. Here TCP is the carrier of thought force $\left(T_{F}\right)$ that is the origin of all the fields. TRP is the origin of all the matter particles. It is to be noted that these TCP and TRP function like wavicle: wave-particle duality. Here thought force $\left(T_{F}\right)$ is an expression of the universal consciousness.

VOID $\rightarrow$ [Big Bang $] \rightarrow[$ TCP, TRP \& Anti-TRP in the inherent presence of thought force $\left.\left(\mathrm{T}_{\mathrm{F}}\right)+\mathrm{STC}\right] \rightarrow$ [Universal Mind with universal consciousness + TCP \& TRP in the inherent presence of thought force $\left.\left(\mathrm{T}_{\mathrm{F}}\right)+\mathrm{STC}+\mathrm{UTF}\right] \rightarrow$ [Universal Mind with universal consciousness + Matter and Fields including thought force $\left.\left(\mathrm{T}_{\mathrm{F}}\right)\right\}+\mathrm{TCP} \& \mathrm{TRP}+\mathrm{STC}+$ $\mathrm{UTF}] \rightarrow$ Universal Mind with universal consciousness + Matter and Fields $\left\{\right.$ including thought force $\left.\left(\mathrm{T}_{\mathrm{F}}\right)\right\}+$ Life as well as consciousness + TCP \& TRP + STC + UTF [where thought force $\left(\mathrm{T}_{\mathrm{F}}\right)$ is the origin of all the fields, TCP (Though-carrying particle) is the origin of all the field particles, TRP (Thought retaining particle) is the origin of all the matter particles, anti-TRP is the origin of all the antiparticles, $\mathrm{STC}=$ Space time continuum and UTF $=$ Universal thought frequency $\cong$ frequency of the TCP].

Physicists determined that underlying quantum fields give birth to elementary particles. Bhaumik [4] mentioned that Frank Wilczek pointed out, "In quantum field theory, the primary elements of reality are not individual particles, but underlying fields. Thus, for example, all electrons are but excitations of an underlying field, naturally called electric field". The same holds true for all the fundamental particles 
of which matter is made.

The existence of matter depends on the existence of force and vice versa. TCP cannot exist without TRP and vice versa. Many physicists believe that unifying all the forces, including gravity, into a single theory would require a phenomenon called super-symmetry. With super-symmetry, every fermion would have a boson twin, and vice-versa. The thought force $\left(\mathrm{T}_{\mathrm{F}}\right)$ is carried by the TCP in the presence of its super-symmetrical partner TRP. TCP that behaves like boson should accompany its super-symmetrical partner TRP that functions like fermion in the generalized simpler way. It is to be noted that these TCP and TRP function like wavicle: wave-particle duality.

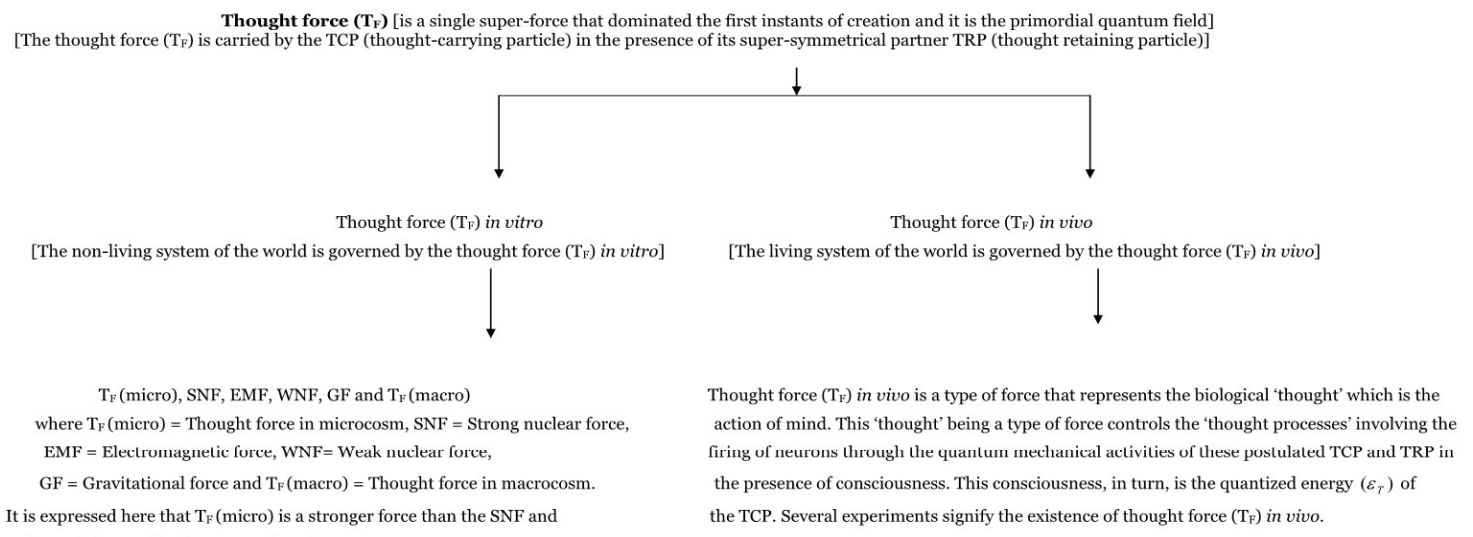

$\mathrm{T}_{\mathrm{F}}($ macro) is a weaker force even than the GF.

Scheme-II: Thought force and its significant roles: Most physicists believe that a single super-force dominated the first instants of creation. This mysterious super-force is the postulated Thought force $\left(T_{F}\right)$. It is possible that the evolution of all the fundamental fields is originated from this super-force that is the Thought force $\left(T_{F}\right)$ in our view. This thought force $\left(T_{F}\right)$ is carried by the TCP (thought-carrying particle) in the presence of its super-symmetrical partner TRP (thought retaining particle). TCP is the carrier of thought force $\left(\mathrm{T}_{\mathrm{F}}\right)$ that, in turn, is the origin of all the fields. TCP is the origin of all the field particles. TRP is the origin of all the matter particles. TCP cannot exist without TRP and vice versa. Our consciousness model involving TCP, TRP and thought force $\left(\mathrm{T}_{\mathrm{F}}\right)$ signifies the existence of universal consciousness that exists along with the universe. We showed that the quantized energy $\left(\varepsilon_{T}\right)$ of the TCP is responsible to cause the universal consciousness as well as the cosmic microwave background radiation temperature. The individual consciousness owes its origin to the universal conscionsness created hy the same $s_{T}$. The same $s_{T}$ is the energy responsible for generating Thought force $\left(T_{F}\right)$. Thus, Thought force $\left(T_{F}\right)$ is an expression of the universal consciousness. Thought force $\left(\mathrm{T}_{\mathrm{F}}\right)$ being an expression of the universal consciousness is applicable to any inanimate object as well as to any biological system (having thinking ability). The Thought force $\left(\mathrm{T}_{\mathrm{F}}\right)$ exerts its functions both in vitro and in vivo. The non-living system of the world is governed by the thought force $\left(\mathrm{T}_{\mathrm{F}}\right)$ in vitro and this Thought force $\left(\mathrm{T}_{\mathrm{F}}\right)$ in vitro gives rise to $\mathrm{T}_{\mathrm{F}}($ micro), $\mathrm{SNF}$, $\mathrm{EMF}$, $\mathrm{WNF}, \mathrm{GF}$ and $\mathrm{T}_{\mathrm{F}}\left(\right.$ macro) where $\mathrm{T}_{\mathrm{F}}(\mathrm{micro})=$ Thought force in microcosm, $\mathrm{SNF}=$ Strong nuclear force, $\mathrm{EMF}=$ Electromagnetic force, $\mathrm{WNF}=$ Weak nuclear force, $\mathrm{GF}=$ Gravitational force and $\mathrm{T}_{\mathrm{F}}$ (macro) $=$ Thought force in macrocosm. It is to be noted here that $\mathrm{T}_{\mathrm{P}}(\mathrm{micro})$ is a stronger force than the SNF and $T_{F}$ (macro) is a weaker force even than the GF. The living system of the world is governed by the thought force $\left(\mathrm{T}_{\mathrm{F}}\right)$ in vivo and this Thought force $\left(\mathrm{T}_{\mathrm{F}}\right)$ in vivo is a type of force that represents the biological 'thought' which is the action of mind. This 'thought' being a type of force controls the 'thought processes' involving the firing of neurons through the quantum mechanical activities of these postulated TCP and TRP in the presence of consciousness. This consciousness, in turn, is the quantized energy $\left(\varepsilon_{T}\right)$ of the TCP. Thought force $\left(\mathrm{T}_{\mathrm{F}}\right)$ being the primordial quantum field functions as the original single primary unified field that is not only the origin of all the four fundamental fields along with both the $\mathrm{T}_{\mathrm{F}}$ (micro) and $\mathrm{T}_{\mathrm{F}}$ (macro) but also the origin of Thought force ( $\mathrm{T}_{\mathrm{F}}$ ) in vivo.

Note: What was previously called a force is now usually called a field or interaction. The existence of matter depends on the existence of force and vice versa. Matter particles are usually designated as "Fermions", because they follow Fermi-Dirac Statistics. Matter particles obey Pauli's exclusion principle; they are of spin $1 / 2$. Force particles are usually designated as "Bosons", because they follow Bose-Einstein Statistics. Force particles do not obey Pauli's exclusion principle; they are of spin o, or any integer like 1, 2, 3 etc. TCP cannot exist without TRP and vice versa. Many physicists believe that unifying all the forces, including gravity, into a single theory would require a phenomenon called super-symmetry. With super-symmetry, every fermion would have a boson twin, and vice-versa. TCP that behaves like boson should accompany its super-symmetrical partner TRP that functions like fermion in the generalized simpler way.

\section{Thought Force}

Pal et al [1,3] and Pal [5] explained the existence of thought force $\left(\mathrm{T}_{\mathrm{F}}\right)$. Thought force $\left(\mathrm{T}_{\mathrm{F}}\right)$, an expression of the universal consciousness, is the primordial quantum field that, in turn, functions as the primary unified field. This $\mathrm{T}_{\mathrm{F}}$ being an expression of the universal consciousness is applicable to any inanimate object as well as to any biological system (having thinking ability). Thus the $\mathrm{T}_{\mathrm{F}}$ being an expression of the universal consciousness exerts its functions both in vitro and in vivo (see Scheme-I and Scheme-II).

Physicists determined that underlying quantum fields give birth to elementary particles. Pal [5] expressed that the thought force $\left(\mathrm{T}_{\mathrm{F}}\right)$ is the primordial quantum field. Thought force $\left(\mathrm{T}_{\mathrm{F}}\right)$ being the primordial quantum field functions as the primary unified field. Thought force $\left(\mathrm{T}_{\mathrm{F}}\right)$ being the primordial quantum field gives birth to TRP that appears to be the origin of all the matter particles. TCP is the carrier of thought force $\left(\mathrm{T}_{\mathrm{F}}\right)$ that, in turn, appears to be the origin of all the fields. TCP thus appears to be the origin of all the field particles.

In a purpose to involve both the non-living and living systems of the world, Pal [5] has shown the existences of these TCP, TRP and thought force $\left(\mathrm{T}_{\mathrm{F}}\right)$ in vitro and thought force $\left(\mathrm{T}_{\mathrm{F}}\right)$ in vivo. Anyone can call this TCP by any other name, but as the highly developed living system will have to be evolved in the universe in the long run and as the thought of highly developed living system appears to be a kind of force to be called the thought force $\left(\mathrm{T}_{\mathrm{F}}\right)$ in vivo, we considered it is wise to call it as TCP. Further, as the universe exists along with the universal consciousness that, in turn, is 
created by the quantized energy $\left(\varepsilon_{T}\right)$ of TCP, we had to use the term TCP.

Pal (5) expressed that the non-living system of the world is governed by the thought force $\left(\mathrm{T}_{\mathrm{F}}\right)$ in vitro and this Thought force $\left(\mathrm{T}_{\mathrm{F}}\right)$ in vitro gives rise to $\mathrm{T}_{\mathrm{F}}$ (micro), SNF, EMF, WNF, $\mathrm{GF}$ and $\mathrm{T}_{\mathrm{F}}$ (macro) where $\mathrm{T}_{\mathrm{F}}$ (micro) $=$ Thought force in microcosm, $\mathrm{SNF}=$ Strong nuclear force, $\mathrm{EMF}=$ Electromagnetic force, $\mathrm{WNF}=$ Weak nuclear force, $\mathrm{GF}=$ Gravitational force and $\mathrm{T}_{\mathrm{F}}$ (macro) $=$ Thought force in macrocosm. It is to be noted here that $\mathrm{T}_{\mathrm{F}}$ (micro) is a stronger force than the SNF and $\mathrm{T}_{\mathrm{F}}$ (macro) is a weaker force even than the GF.

Pal (5) also expressed that the living system of the world is governed by the thought force $\left(\mathrm{T}_{\mathrm{F}}\right)$ in vivo and this Thought force $\left(\mathrm{T}_{\mathrm{F}}\right)$ in vivo is a type of force that represents the biological 'thought' which is the action of mind. This 'thought' being a type of force controls the 'thought processes' involving the firing of neurons through the quantum mechanical activities of these TCP and TRP in the presence of consciousness. Consciousness in living organisms is a process which involves the quantum mechanical activities of these TCP and TRP, the ultimate constituents of any matter as well as any mind in the inherent presence of thought force $\left(\mathrm{T}_{\mathrm{F}}\right)$ in vitro and the thought force $\left(\mathrm{T}_{\mathrm{F}}\right)$ in vivo as indicated by Pal et al [3]. This consciousness, in turn, is the quantized energy $\left(\varepsilon_{T}\right)$ of TCP. The thought force $\left(\mathrm{T}_{\mathrm{F}}\right)$ in vivo is demonstrated in numerous experiments in which thought has an effect on a physical process (often known as mind over matter). This biological 'thought' is a type of force that can cause movement. Controlling movement through thought alone is observed in several experiments conducted by many scientists as indicated by Pal (5). These experiments thus signify the existence of thought force $\left(\mathrm{T}_{\mathrm{F}}\right)$ in vivo.

Pal [5] explained the existence of $\mathrm{T}_{\mathrm{F}}$ (micro) (= Thought force in microcosm). This $\mathrm{T}_{\mathrm{F}}$ (micro) is the strongest interaction (a new class of 'extra strong' interaction). It is stronger than SNF (Strong Nuclear Force).

Pal [5] has also shown the existence of $\mathrm{T}_{\mathrm{F}}$ (macro) $(=$ Thought force in macrocosm). It is the "weakest force" which is much weaker even than the gravity.

2.1. Pal et al [3] developed three different equations expressing the quantized energy ( $\left.\varepsilon_{T}\right)$ of TCP. The value of $\varepsilon_{T}$ in one of the three equations is shown below:

$$
\mathcal{E}_{T}=4.384 \times 10^{-16} \mathrm{erg} \equiv 2.73 \times 10^{-4} \mathrm{eV} \equiv 2.73 \mathrm{~K} \cong C M B R \text { temperature } \equiv 2.725 \mathrm{~K} .
$$

This conversion of erg $\equiv \mathrm{eV} \equiv \mathrm{K}$ is given by Weisskopf [6] as follows:

$$
1 e r g \cong 0.6241807 \times 10^{12} \mathrm{eV} \text { and } 10^{-4} \mathrm{eV} \cong 1 \mathrm{~K}
$$

2.2. Pal et al [3] expressed that the CMBR temperature is due to $\varepsilon_{T}$, the quantized energy of TCP where

$$
\varepsilon_{T}=4.384 \times 10^{-16} \mathrm{erg} \equiv 2.73 \times 10^{-4} \mathrm{eV} \equiv 2.73 \mathrm{~K} \cong C M B R \text { temperature } \equiv 2.725 \mathrm{~K} .
$$

As per Pal et al [3], it is interesting to note that all of the three different equations ultimately give rise to the same result that is equivalent to the CMBR temperature. A sort of relationship is thus observed between the $\varepsilon_{T}$ and the CMBR temperature. This coincidence is thus signifying a probable role of TCP on the maintenance of CMBR temperature. Further, this coincidence is also signifying the existence of these TCP in the presence of TRP. TCP cannot exist without TRP and vice versa. The presence of TCP, TRP and Thought force $\left(\mathrm{T}_{\mathrm{F}}\right)$ in the universe is thus indicated and expressed mathematically. At present we are unable to explain when and how these TCP and TRP decoupled from the primordial cosmic soup.

Pal et al $[1,3]$ showed that the quantized energy $\left(\varepsilon_{T}\right)$ of TCP is responsible to cause the universal consciousness as well as the cosmic microwave background radiation temperature. The individual consciousness owes its origin to the universal consciousness created by the same $\varepsilon_{T}$. Ultimately this $\mathcal{E}_{T}$ represents universal consciousness. The existence of CMBR temperature indicates the existence of the TCP in the presence of TRP. The existence of TCP ensures the existence of the thought force $\left(\mathrm{T}_{\mathrm{F}}\right)$. Further, this $\mathrm{T}_{\mathrm{F}}$ being an expression of the quantized energy ( $\varepsilon_{T}$ ) of TCP exerts its functions both in vitro and in vivo.

\section{What Is Life}

Life is a state of flux that is being maintained by a typical form of energy which is nothing but the consciousness itself. Pal et al [3] and Pal [7] showed that the quantized energy $\left(\varepsilon_{T}\right)$ of TCP is responsible to cause the universal consciousness as well as the cosmic microwave background radiation temperature. The individual consciousness owes its origin to the universal consciousness created by the same $\varepsilon_{T}$. Pal et al $[1,3]$ and Pal [7] explained that life may be defined as a state of functional manifestation of consciousness that, in turn, is the quantized energy ( $\left.\varepsilon_{T}\right)$ of TCP. This $\boldsymbol{\varepsilon}_{T}$ represents universal consciousness.

Thus,

$$
\text { Life }=\mathrm{f}(\text { Consciousness })=\mathrm{f}\left(\boldsymbol{\varepsilon}_{T}\right)
$$

where $\mathcal{E}_{T}=$ quantized energy of the TCP $=4.384 \times 10^{-16} \mathrm{erg}$.

$$
\varepsilon_{T}=h v_{T}=h c / \lambda_{T}=4.384 \times 10^{-16} \mathrm{erg}
$$


where

$\varepsilon_{T}=$ quantized energy of the TCP $=4.384 \times 10^{-16} \mathrm{erg}$,

$v_{T}=$ frequency of the TCP $=\varepsilon_{T} / h=66.12 \times 10^{9} \mathrm{~Hz} .=66.12 \mathrm{GHz}$,

$\mathrm{h}=$ Planck's quantum constant $=6.63 \times 10^{-27} \mathrm{erg} . \mathrm{sec}$,

$\mathrm{c}=$ free-space velocity of light $=3 \times 10^{10} \mathrm{~cm} / \mathrm{sec}$,

$\lambda_{T}=$ wave-length of the $\mathrm{TCP}=0.4537 \mathrm{~cm}$.

\subsection{What Is Consciousness}

Psychologists, neuroscientists, philosophers, and other professionals continue to engage in an ongoing debate as to what consciousness means. In reality, we may never know. Is it a product of the biological and classical physical interactions of the human brain; or is it something more fundamental, perhaps electromagnetic, or the result of quantum physics principles that we don't yet fully understand? Could it be something even more profound than that -something beyond the scope of science and physics, any kind of physics, for us to understand?

According to the ancient Vedanta, consciousness is not an emergent property of matter that comes into existence only through the functioning of the human nervous system. Instead, consciousness is a characteristic of reality, pervading all manifestations. This unbounded field of nature's universal consciousness is not limited to an individual consciousness. From this viewpoint, the role of the human nervous system is to provide an appropriate material structure to individualize the universal consciousness. It appears that inanimate matter itself cannot generate consciousness without the inherent existence of universal consciousness. Consciousness in living organisms is a process which involves the quantum mechanical activities of these TCP and TRP, the ultimate constituents of any matter as well as any mind in the inherent presence of thought force $\left(\mathrm{T}_{\mathrm{F}}\right)$ in vitro and the thought force $\left(\mathrm{T}_{\mathrm{F}}\right)$ in vivo as indicated by Pal et al $[1,3]$. And these TCP and TRP govern the activities of neurons (not the other way round). Neurons are simply the equipments used to generate consciousness and awareness.

Pal et al [2] explained, "Consciousness is the realization of existence, and there are as many states of consciousness as there are states of existence. Every living being has a consciousness of its own depending on complexity of the brain and the activity of the viable numbers of TCP in the presence of TRP; and the state of its consciousness changes every moment of time. Consciousness is the perception of the relation it bears to things and as this relation changes, consciousness changes its character. Consciousness itself does not change; it only moves up and down on the 'scale of the realization' of existence through the 'sub-conscious', 'conscious' and 'super-conscious' states". There is another term called unconscious state. The most usual unconscious state is sleep. A deeper form of unconsciousness is called a coma.

It appears that

$$
\text { Consciousness }=\mathrm{f}(\mathrm{mind})
$$

Consciousness is the functional state of mind. Presence of consciousness signifies the presence of mind and vice versa.
It is apparent that

$$
\text { Animate } \neq \text { Inanimate }
$$

Three critical factors which distinguish life from nonliving are consciousness, metabolism and reproduction.

In a gross presentation, we can express from the equation (4):

$$
\text { Animate }- \text { Consciousness }=\text { Inanimate }
$$

Scientists would have to define and characterize consciousness properly. We should have the proper knowledge about the exact characteristics of consciousness in order to address many present day scientific enigmas.

\section{What is the Exact Definition of Mind? What is Mind?}

We observe a great controversy concerning the exact definition of mind. There are two apparently opposite views: one is the substantial view and the other is the functional view.

In the substantial view, the mind is a type of substance. Mind is a finer matter having an autonomous existence. Mind is a single entity, perhaps having its base in the brain but distinct from it. In its most extreme form as in the Indian Upanishads and Vedanta, the mind is not only a finer matter but also it is an entity wholly separate from the body, in fact a manifestation of the soul, which will survive the body's death in the form of the spiritual body or mental body [called Linga Sharira or Sukshma Sharira in Sanskrit] as expressed by Vivekananda [8] who indicated that this mental body bears all the mental impressions. This mental body is also called 'spirit'.

In the functional view, the mind is closely related to the functions of the brain and can have no autonomous existence beyond the brain, nor can they survive its death. In this view, mind is a 'state' created by the activities of the brain with other parts of the nervous system as it is indicated by cognitive neuro-scientists and Artificial Intelligence (AI) scientists. According to them 'minds are simply what brains do'. In this functional view, mind is a subjective manifestation of consciousness: the human brain's ability to be aware of its own existence. The concept of the mind is therefore a means by which the conscious brain understands its own operations.

The modern cognitive neuroscientists generally accept the fact that the "mind" is not an isolated entity and the mind is a state created by the activities of brain with other parts of the nervous system (CNS, PNS along with ANS). Although the mind is generally accepted to be an abstract having no spatial location or public observability, yet it is a type of fine matter according to the ancient Indian Upanishads and Vedanta. The Vedanta indicates that the universe exists along with the universal consciousness. This universal consciousness is a functional state of the Universal Mind. Pal et al [1, 3] explained that any matter as well as any individual mind is constituted by these TCP and TRP in the inherent presence of Thought force $\left(\mathrm{T}_{\mathrm{F}}\right)$ in vitro and Thought force $\left(\mathrm{T}_{\mathrm{F}}\right)$ in vivo. It 
is to be noted that these TCP and TRP are the ultimate constituents of any matter in the inherent presence of thought force $\left(\mathrm{T}_{\mathrm{F}}\right)$ in vitro. And these TCP and TRP are the ultimate constituents of any mind in the inherent presence of thought force $\left(\mathrm{T}_{\mathrm{F}}\right)$ in vivo.

Modern Scientists are not yet able to understand how the brain works to make the mind. They know that brain has got neurons that communicate across synapses by releasing a neurotransmitter, and that generates electrical impulses, and the receiving neuron then talks to its neighbor neurons the same way. If the mind depends on the brain, then all aspects of the mind are going to depend on these simple electrical, chemical processes. According to this concept, the existence of the UM requires the existence of the universal brain to form the UM. The concept of universal brain is not logically acceptable. Thus the concept that the mind depends on the brain becomes questionable if the existence of the UM is valid.

The basic mystery of the mind is how does it emerge from pure matter? How do those units that are made of tiny particles, give rise to the unique and essentially private, experience called consciousness? Do the particles that constitute our brain determine what we think and do? Do these tiny particles ultimately govern the thinking ability of the bioelectrical system? Or, are we free to have our own will? Is consciousness just froth sitting on top of the brain's electronics? How consciousness is being operated? Why should a bunch of atoms have thinking ability? Gross answers to all these inquiries are possible if we accept these TCP and TRP as the ultimate constituents of mind and matter as indicated by Pal et al [3].

We are what our minds make us. The mind is a very powerful controller of the body. The mind controls everything as indicated by $\mathrm{Pal}$ et al $[1,3]$ and $\mathrm{Pal}$ [7]. Mind is conditioned from the time we are young. It gives our abilities, our perceptions, our character and the way we think

4.1. It appears that scientists would have to decide in a purpose to conclude clearly whether mind is a 'state' (created by the activities of the brain with other parts of the nervous system as it is indicated by the functional view of mind) or 'a finer matter' (as it is indicated by the Indian Upanishads and Vedanta)

\section{Existence of Universal Consciousness}

Pal et al [3] and Pal [7] have expressed that current scientific views regarding the origin of consciousness vary widely and range from an 'epiphenomenon' arising from neuronal networks, to neuronal quantum processes, to a separate undiscovered scientific entity. Pal et al [3] and Pal [7] have indicated and expressed the existence of universal consciousness.

In a purpose to determine the nature of human mind and consciousness as well as its relationship with the brain, Parnia [9], Lommel [10], Fenwick [11] and Beauregard \& O'Leary [12 \& 13] observed through different lines of experiments and through studies of cardiac arrest survivors that the cerebral functioning as measured by electrical activity of the brain ceases during cardiac arrest. Parnia [9] observed in the cardiac arrest survivors that the human mind and consciousness continue to function in the absence of brain function when there is cardiac arrest. Thus observations in these studies of cardiac arrest survivors raise the possibility that human mind and consciousness may continue to function in the absence of brain function. Lommel [10] in his "About the Continuity of Our Consciousness" mentioned, "The conclusion that consciousness can be experienced independently of brain function might well induce a huge change in the scientific paradigm in western medicine... There are still more questions than answers, but, based on the aforementioned theoretical aspects of the obviously experienced continuity of our consciousness, we finally should consider the possibility that death, like birth, may well be a mere passing from one state of consciousness to another".

According to Beauregard \& O'Leary [12 \& 13], "Mind, consciousness, and self can continue when the brain is no longer functional" and, what is more, that phenomena generally associated with mystical states "can occur when the brain is not functioning".

Parnia [9] said, "...human consciousness, as bizarre as it may sound, could be non-local to the brain", thus signifying the probable existence of universal consciousness, however odd it may sound. Pal et al [1;3] have shown that the individual consciousness owes its origin to the universal consciousness. The nervous system is evolved to individualize this universal consciousness that, in turn, exists along with the universe. The experimental observations of Parnia[9], Lommel [10], Fenwick [11] and Beauregard \& O'Leary $\left[\begin{array}{lll}12 & \& & 13\end{array}\right]$ demonstrate the existence of consciousness during the cessation of brain activity and thus support the existence of universal consciousness as well as substantial view of mind as indicated by the Indian Upanishads and Vedanta.

Pal et al [3] have expressed that according to the modern physicists, the universe is the summation of fields, particles, space-time continuum, dark matter, dark energy, void and all the known and unknown parameters of the universe along with all its inhabitants (with or without consciousness), although the universe is always expanding.

The method of integration indicates that

$$
\int d x=x+c
$$

where $\mathrm{c}=\mathrm{a}$ constant. Is there any mathematical fallacy if we like to use 'universe' in the place of ' $x$ ' here? If we at all theoretically like to apply the same method of integration to the whole universe itself, we will have to arrive at

$$
\int d(\text { universe })=\text { universe }+c
$$

where universe $=$ universe with all its known and unknown parameters as well as its inhabitants (with or without consciousness) and $\mathrm{c}=\mathrm{a}$ constant. The constituents of the universe are fields, particles, space-time continuum, dark matter, dark energy, void, all its inhabitants (with or without consciousness) and all the other unknown parameters of the universe that we have not yet faced. We simply propose to 
apply the method of integration theoretically over the universe as a whole with all its known and unknown parameters and all the inhabitants (with or without consciousness). If we at all theoretically like to do so, we will mathematically arrive at a constant.

What is this constant here? It is our opinion that this constant is the universal consciousness that exists throughout the universe in the form of universe wide web (uww) covering fields, particles, space-time continuum, dark matter, dark energy, void and all its known and unknown parameters along with all its inhabitants (with or without consciousness). This universal consciousness is to be taken into account, but usually ignored.

Many physicists agree with the idea that consciousness is non-local, fundamental in the universe and consciousness is very much a part of the universe, like other objects. It is to be noted that $\varepsilon_{T}$, the quantized energy of TCP represents universal consciousness.

Nelson [14], Director of Global Consciousness Project, has observed through the experimentation that coherent consciousness creates order in the world; and subtle interactions link us with each other and the Earth. When human consciousness becomes coherent and synchronized, the behavior of random systems may change. Quantum event based random number generators (RNGs) produce completely unpredictable sequences of zeroes and ones. But when a great event synchronizes the feelings of millions of people, our network of RNGs becomes subtly structured. The probability is less than one in a billion that the effect is due to chance. The evidence suggests an emerging noosphere, or the unifying field of consciousness described by sages in all cultures. This evidence signifies and proves the existence of universal consciousness.

The existence of universal consciousness is explained by Radin [15] through experimentation as it is expressed in his book The Conscious Universe: The Scientific Truth of Psychic Phenomena. Further, Consciousness, not matter, is the ground of all existence, declares University of Oregon physicist Goswami through his published (1993) book, "The Self-Aware Universe: How Consciousness Creates the Material World".

As per Penrose [16], consciousness is a part of the universe. Van De Bogart [17] explained, "Since consciousness is a part of the universe it then follows that all consciousness, and the universe, are of the same matrix of energy fields". Our consciousness model signifies the existence of universal consciousness that, in turn, is a functional state of the universal mind (UM).

\section{Evolution of Life and Consciousness through the Consciousness Model Involving the Quantum Mechanical Activities of TCP, TRP and Thought Force $\left(T_{F}\right)$ in Vitro and Thought Force $\left(\mathrm{T}_{\mathrm{F}}\right)$ in Vivo}

As several leading scientists have commented the universe is so finely tuned to allowing the emergence of conscious entities that it looks more than mere coincidence.

Davies [18] expressed, "If the basic laws of the universe were just slightly different, life and everything we know would not exist. So why is the universe just right for life? Could the universe have fine-tuned itself in order to bring about life and consciousness? At first sight, the idea seems preposterous. How could the universe in the first split second, when its laws were still malleable, know about the emergence of life billions of years later"?

Barrow and Tipler [19] in their "The Anthropic Cosmological Principle 1986" mentioned the view point of Dyson who pointed out, "The more I examine the universe and the details of its architecture, the more evidence I find that the universe in some sense must have known we were coming". Physical laws clamor for life: the universe knew we were coming. Our universe is perfectly tailored for life.

All these statements simply signify the existence of universal consciousness that is the primary cause for the evolution of life. Without the inherent existence of universal consciousness, the inanimate matter itself cannot generate life and consciousness. These postulated TCP and TRP, the constituents of UM and the ultimate constituents of matter and mind are thus liable to be originated from the Void at the Big Bang to evolve the space-time continuum and UM along with the universal consciousness as indicated by Pal et al [1, 3]. In this way the universe could 'know about' the emergence of life billions of years later. Thought force $\left(T_{F}\right)$, an expression of this universal consciousness, is thus the primordial quantum field (see Scheme-I).

Monod [20] finds that teleonomic purposeful behavior is one of the fundamental characteristics of life, along with what he calls autonomous morphogenesis (life is "selfconstructing") and reproductive invariance (life is "selfreplicating").

Monod [20] says that some biologists have been unhappy with his idea of teleonomy that living beings are endowed with a purpose or a project, but he says this is essential to the definition of living beings. His next criterion is autonomous morphogenesis.

Information philosophy agrees that with the emergence of life, information structures with purposes entered the universe.

Emotions, 'living force', mind, consciousness and soul are the characteristics of life. How all the characteristics of life are related to life on the basis of its evolution from the inanimate matter? Orders and arrangements of atoms and molecules are thought to be the main characteristics required to form molecules necessary to evolve 'life'. Physicochemical properties of atoms and molecules are thought to be responsible for those orders and arrangements.

Ilya Prigogine $[21,22]$ is noted for his work on dissipative structures, complex systems, and irreversibility. He [21, 22] is famous for his "Self-Organization in Non-Equilibrium Systems" and "From Being To Becoming". He won a Nobel Prize in 1977 for his work demonstrating the fact that certain chemical systems, called 'dissipative structures,' naturally increase rather than decrease their complexity without violating the Law of Entropy. They accomplish this by 
exchanging energy for order, so that overall entropy still increases even as order is produced.

But what is the driving force to develop and maintain all those orders and arrangements in order to evolve 'life'? Is there any purpose? Ordering effects must be the result of some kind of intelligence. It appears that the over-all-order and arrangements of atoms and molecules are governed by the quantum mechanical activities of these TCP and TRP as per the directive of the universal mind (UM). This UM, in turn, is evolved from the eternal Void indicated by Pal et al [3]. The universal consciousness that is a functional state of the UM functions as the evolutionary force to promote the bio-field.

The science of the mind may be connected with the science of the body. It is possible that the modern mind has been developed to get its present shape by the directive of the UM. The mind is an all-purpose computer responding impartially to the world around it; and this mind had, through natural selection, evolved to respond in a particular way to particular environmental circumstances. Humans are 'adaptation executors' carrying out programs written into the mind's machinery long ago. "The machinery does not know its own programming", said Cosmides and Tooby [23-25], intellectual leading evolutionary psychologists. The evolutionary psychologists see the mind as pre-programmed, made up of specialized mechanisms---'modules' or 'organs'. The evolutionary psychologists argue that their job is to approach the mind as an ancient engineering project, developing and testing out hypotheses about what 'designed problems' needed solving. Such an approach offers a badly needed bridge between psychology and the natural sciences. A plausible bridge between psychology and the natural sciences can be achieved through the developed consciousness model.

Biological system is a complex information processing system. Davies [26] wrote in his 'The Fifth Miracle', the "necessary powers to produce life" could be "already implicit in the laws of physics themselves. Imagine life emerging from a soup in the same dependable way that a crystal emerges from a saturated solution". Indeed, when we consider some of nature's universal constants, such as G (gravitational constant) and h (Planck's quantum constant), it is eerie to consider that life as we know it could not have evolved had any of these constants been different by even a miniscule amount. Does this tell us something about how closely life is connected to the laws of nature and that the evolution of life is predetermined? Davies [26] expressed that life's distinctiveness does not lie in its chemical properties but in its "informational properties". A living organism is a complex information processing system. Life was sparked not by a molecular maelstrom but, somehow, by the organization of information. The introduction of information into the molecule leads to increased order, and therefore less entropy. The molecule 'drinks' information from the surroundings to transform a chemical entity into a molecule of life. This process is remarkable because it goes against the second law of thermodynamics, which is a universal law.

Further, the values of the fundamental constants--- the parameters of particle physicists' "standard model" --- must adopt narrowly defined ranges for our life-supporting world to emerge. They arrange themselves precisely for the fostering of stars, and therefore life, within the universe. What caused this arrangement? Some would ask, "Who arranged them?" To some observers, the fine-tuning of the fundamental constants suggests the universe as an artifact: the universe had a creator. The universe bears the footprint of God which, in our view, is the eternal Void. And Stephen Hawking's phrase--the 'mind of God', in our view, is constituted and operated by these TCP and TRP in the presence of the thought force $\left(\mathrm{T}_{\mathrm{F}}\right)$ in vitro and thought force $\left(\mathrm{T}_{\mathrm{F}}\right)$ in vivo.

The key to understanding life lies in explaining how DNA was formed. What brought about the ordered structure of the DNA, why the code uses four types of bases (Adenine, Thymine, Guanine, Cytosine) and not three or five, what did the earliest DNA's look like etc. are among the questions to be answered. Wigner [27, 28] had explained that a physical system could not make a transition from a non-living to a living state without contravening the laws of quantum physics. The inter-atomic forces that form biological molecules like proteins and DNA/RNA must be quantum mechanical in nature. Thus quantum theory involving the quantum mechanical activities of these TCP and TRP may decidedly help in understanding the evolution of life and consciousness.

What is evolved in biological evolution? That which is involved initially is going to be evolved gradually. This should be the most logical aspect of the so-called biological evolution. Vivekananda [29] mentioned, "The sum total of the intelligence displayed in the universe must be the involved universal intelligence unfolding itself'.

The 'life' can be identified as the ability to reproduce. The characteristics of life include reproduction, metabolism and nutrition, complexity organization, growth, development, information content, autonomy (self-determination) in the presence of unique consciousness. Despite so many markers, recognition of what is life is still hazy. There is no sharp dividing line between living and non-living systems, though three critical factors distinguish life---consciousness, metabolism and reproduction.

The basic questions that need to be answered are when, where and how did life begin? Also, what helps non-living matter to make the leap to become a living entity and how does this transformation take place? Solving these riddles is central to explaining the origin of life and getting an answer to the crucial question: Are we alone? It is known that proteins are produced by the instructions contained in the DNA (Deoxyribonucleic acid). Each DNA contains a complete set of instructions on how to build a living body. But the most extraordinary property of this molecule is its ability to replicate, that is, to make copies of itself, a fundamental requirement of life. The DNA is an extremely ancient molecule, almost as old as the earliest form of life detected on earth. Under what conditions was the DNA first produced, is the central mystery of life. We know that DNA makes RNA which makes proteins. But genetic material can only be made with the help of enzymes which are proteins 
themselves. What came first---genetic material or proteins? It has been observed that some RNA molecules can also act as enzymes and this unique observation has led to something called the RNA world hypothesis.

It was believed that in the pre-biotic world, RNA originated first, earlier than the proteins, and mediated reactions necessary for a precursor of life. A fair amount of evidences has lent credence to the suggestion that the prebiotic world was dominated by the RNA world and subsequently followed by the advent of life---based on DNA, RNA and protein. Takagi et al [30] in their work on ribozyme elucidated the existence of RNA world, in the pre-biotic soup.

What force causes DNA to give proper instructions for controlling the normal 'cellular function' through the formation of specific sequence which, in turn, is responsible for the transportation of newly-formed proteins to specific locality? It is known that a cell is a complex organization of proteins, but we do not know how those proteins came together to form the first complex web that is a living cell. The most abundant forms of life on earth are microbes. The life on earth could either have evolved deep underground or may have been introduced from outer space. Life could have reached earth, pre-evolved, riding on a gas cloud or resident on a meteorite. But how did life come into being? If it was a one off accident, whose possibility is extremely remote, then are we alone in the universe and is earth the chosen planet where this impossible event had happened? May be the "accident of life" happened elsewhere.

If life is not to be treated as an accident, we have to subscribe to the hypothesis of biological determinism. Davies [26] wrote in his 'The Fifth Miracle', the "necessary powers to produce life" could be "already implicit in the laws of physics themselves. Imagine life emerging from a soup in the same dependable way that a crystal emerges from a saturated solution".

\section{Evolution of Consciousness through the Consciousness Model Involving TCP, TRP and Thought Force $\left(T_{F}\right)$ in Vitro and Thought Force $\left(\mathrm{T}_{\mathrm{F}}\right)$ in Vivo}

Pal et al [3] expressed that the evolution of life with mind and consciousness is possible purely due to the inherent existence of universal consciousness which exists along with the universe. The human nervous system is evolved to provide an appropriate material structure to individualize the universal consciousness, a characteristic of reality, pervading all manifestations. According to the ancient Vedanta, everything in this universe is a manifestation of the universal mind (UM), the functional state of which is the universal consciousness. The consciousness model of Pal et al. [3] signifies the existence of universal consciousness that, in turn, is created by the quantized energy ( $\left.\varepsilon_{T}\right)$ of TCP. The quantized energy ( $\varepsilon_{T}$ ) of TCP is found to create the cosmic microwave background radiation (CMBR) temperature along with the universal consciousness.

\section{Consciousness May be Defined as the 'Self-Organized' Capability of any Living being to Activate TCP and TRP}

Pal et al [3] expressed that consciousness may be defined as the 'self-organized' capability of any living being to activate TCP and TRP, the ultimate constituents of any matter as well as any mind and to exert its functions. What can generate, maintain and activate TCP and TRP is called animate having 'active consciousness' and what cannot is called inanimate, i.e., devoid of active consciousness. As anything inanimate does neither have the power to activate the TCP and TRP nor have the capability to catalyze the activity of TCP and TRP, so it cannot generate consciousness On the contrary, anything animate has the 'self-organized' power to generate, activate and catalyze the activity of TCP and TRP in order to generate and maintain consciousness along with the vital living force. Prigogine et al [21] explained "Self-Organization in Non-Equilibrium Systems".

Consciousness in living organisms is a process which involves the quantum mechanical activities of these TCP and TRP, the ultimate constituents of any matter as well as any mind in the inherent presence of thought force $\left(\mathrm{T}_{\mathrm{F}}\right)$ in vitro and thought force $\left(\mathrm{T}_{\mathrm{F}}\right)$ in vivo. And these TCP and TRP govern the activities of neurons (not the other way round). These neurons are simply the equipments used to generate consciousness and awareness. The consciousness itself is functioning as an inter-linking agent between the animate and inanimate through the quantum mechanical activities of these TCP and TRP indicated by [3].

\section{Virus is an Intermediate between Living and Non-Living}

In order to understand the difference between anything animate and inanimate, it would be logically plausible to consider the case of virus that is an intermediate between the living and non-living. In the extra-cellular phase, the virus functions like non-living object that can even be crystallized. In the intracellular phase within the host cell, the same virus behaves like animate. The virus in the intracellular phase is capable of producing replication. It is thus clear that in order to maintain the "life function", the nucleoprotein containing DNA/RNA of the virus would either have to remain within a type of field or "energy" called consciousness or have to generate the quantized energy of the order of $10^{-16} \mathrm{erg}(=$ quantized energy of TCP $=\varepsilon_{T}$ ) for the initiation of consciousness directly.

As the invaded cell of the host can supply the required field or 'energy', so the nucleoprotein containing DNA/RNA of the virus which is within this field can manifest the function of "life". It may be the same case with the bacteriophage, which attacks bacteria. 


\subsection{Life without Consciousness Is not Possible}

Although it appears to be enigmatic, yet it is to be noted that life without consciousness is not possible due to the existence of universal consciousness through the function of which life is liable to be evolved in the universe.

Now, the question arises whether all these typical creatures like microbes or plants would have the potential optimum consciousness of their own levels or not. Are they themselves capable of maintaining the critical state to catalyze the activity of TCP and TRP for the generation of consciousness that is responsible for maintaining the "life function"? It is apparent that if they do not have the consciousness at all, they would not fight for the survival - - - they would not hanker after food they require for their growth or they would not go to carry on reproduction or replication. Anything inanimate would not be found to do so. Thus it is obvious that the presence of "life function" means the presence of at least 'potential consciousness', the best functional center of which is the organized brain achieved through the process of 'biological evolution'. As the lowest developed living beings like microbes and plans do not have organized brain, so they do not have the instrumental power (like highly developed organized living beings) to catalyze the normal activities of TCP and TRP for which there is insignificant external manifestation of consciousness.

The virus itself is the source of many lively scientific debates. To live means to use energy, some have argued, to metabolize, to eat. Viruses do none of these things. A group of virologists indicate that viruses secondarily metabolize, by forcing their host cells to devote most of their metabolic energy to the production of new viruses. "Viruses are smart enough to direct their reproduction," said Levine [31-34] "I have always thought of them as alive, although in a dormant state."

In the case of the bacteria, it is difficult to define a specific structure through which consciousness is expressed. But it is obvious that in the absence of operational consciousness they would not fight for the survival, they would not hanker after food or they would not go to carry on reproduction or replication.

Mater Jr. [35] in his "Our Intelligent Companions, the Plants" pointed out, "The great Bengali scientist, Sir Jagadis Chundra Bose, conducted fascinating experiments with plants nearly a hundred years ago. Dr. Bose combined physiology, physics, and biology in his research and discovered universal relationships. He devised a way for a plant, by reacting to electrical and other stimuli, to "write" its signature on a piece of smoked glass. He observed that the sensitive mimosa has a reflex arc like an animal, and a type of nervous system of its own corresponding to certain cells. Bose quotes the following from Henri Bergson: "it by no means follows that a brain is indispensable to consciousness. . . . If then, at the top of the scale of living beings, consciousness is attached to very complicated nervous centres, must we not suppose that it accompanies the nervous system down its whole descent, and that when at last the nerve stuff is merged in the yet undifferentiated living matter, consciousness is still there, diffused, confused, but not reduced to nothing? Theoretically, then, everything living might be conscious. In principle, consciousness is coextensive with life".

As per Geddes [36], Bose found that every plant and every part of a plant appeared to have a sensitive nervous system and responded to shock by a spasm just as an animal muscle does. Bose found through his experiments that plants grew more quickly amidst pleasant music and more slowly amidst loud noise or harsh sounds. Bose also claimed that plants can "feel pain, understand affection etc.," from the analysis of the nature of variation of the cell membrane potential of plants under different circumstances. According to him, a plant treated with care and affection gives out a different vibration compared to a plant subjected to torture. In conclusion, he said: "Do not these records tell us of some property of matter common and persistent? That there is no abrupt break, but a uniform and continuous march of law? Bose's experiments stopped at this conclusion, but Backster [37] conducted research that led him to believe that plants can communicate with other life forms. He came to the resolution that, if he was correct, plants can not only feel things, but can also, in effect, perceive a person's intent as it relates to the plant itself.

A little known report called "Organic Biofield Sensor" was published by Puthoff and Fontes [38]. This report supports the possibility that plants may respond to human consciousness as contended by Backster [37].

Mater Jr. [35] mentioned "Bose went even further in his experiments showing us new interrelationships between the "living" and "non-living" that are not yet fully recognized, and that consciousness is in all matter. His experiments primarily reveal a plant awareness very sensitive to other types of electromagnetic frequencies or waves besides those of visible light".

The conclusions through observations of Mater Jr. [35], Geddes [36], Backster [37] and Puthoff and Fontes [38] indicate that plants can not only feel things, but can also, in effect, perceive a person's intent as it relates to the plant itself and plants can communicate with other life forms and thus signify that plants posses some kind of consciousness, although they do not have organized brain. In this way, it is a fact that life without consciousness is not possible due to the existence of universal consciousness through the function of which life is liable to be evolved in the universe.

\section{Generation of "Life" from the Non-Living Materials}

In order to interpret the generation of "life" from the nonliving materials it is easy to understand that macromolecules of nucleoprotein containing DNA/RNA are to be produced, first of all, by any means. This RNA or DNA containing information and instruction may be created by the quantum mechanical activities of these TCP and TRP as per the directive of UM, the functional state of which is the universal consciousness. And then these macromolecules will have to create a 'critical state' within themselves so as to initiate the "self-generation" of the quantized energy of at least of the order of $10^{-16} \mathrm{erg}$ (= quantized energy of TCP $=\mathcal{E}_{T}$ ). This is required for catalyzing the activity of TCP and TRP for the 
direct generation of consciousness as well as the 'Vital Living Force' in order to maintain a state of flux which is known as "life".

Researches are being conducted on the 'live fishes' in the Antarctic and other oceans to understand the physiological and biochemical changes which are caused to them when they are forced to encounter stress during the ecological and environmental changes. It is a plausible question: How "live fishes" in the extreme climate are able to maintain the "life function" during the winter when the water in which the fishes would have to live is frozen to ice? Is it true that they are automatically "recharged" to "life" when the ice melts during the summer? It is to be noted that a plant grows (when maintained in suitable condition) from the apparently inert speed which is nothing but a potential form of plant life. Heat energy itself may play a fundamental role through the supply of energy of the order of $10^{-16} \mathrm{erg}$ (= quantized energy of TCP $=\mathcal{E}_{T}$ ) to catalyze the activity of TCP and TRP in these specific cases where there is a significant scope to initiate the function of "life". Are they then the specific phenomena of typical hibernation? There is the generation of "life function" as soon as there is the "self-generation", by any means, of the quantized energy of the order of $10^{-16} \operatorname{erg}$ (= quantized energy of $\mathrm{TCP}=\varepsilon_{T}$ ) for the initiation of the quantum mechanical activities of these TCP and TRP. It is obvious that there is the manifestation of "life function" as soon as there is the initiation of consciousness through the quantum mechanical activities of these TCP and TRP by any means. Further, the existence of life is impossible without the functional presence of DNA or RNA.

\section{The Evolution of Animate from Inanimate can be grossly expressed as Follows Through the Functional Quantum Mechanical Activities of these TCP and TRP in the Presence of Thought Force $\left(\mathrm{T}_{\mathrm{F}}\right)$ in Vitro and Thought Force $\left(\mathrm{T}_{\mathrm{F}}\right)$ in Vivo}

TCP and TRP with thought force $\left(\mathrm{T}_{\mathrm{F}}\right)$ in vitro in Inanimate $\rightarrow$ [Orders of atoms through dissipative structures (of Prigogine) maintained by the quantum mechanical activities of these TCP and TRP as per the directive of UM, the functional state of which is the universal consciousness] $\rightarrow$ RNA or DNA $\rightarrow$ Animate with thought force $\left(\mathrm{T}_{\mathrm{F}}\right)$ in vivo.

Life is thus the product of hydrocarbons as indicated by Thomas Gold, of course, through the quantum mechanical activities of these TCP and TRP as per the directive of UM, the functional state of which is the universal consciousness. Delbruk [39] pointed out, "The break between the non-living world and the living world might not be absolute".

\section{Discussions and Conclusion}

\subsection{Discussions}

Capra [40] pointed out, "If we look at theories of consciousness, we can see that most of them are variations of two seemingly opposite views. One of these views I will call the Western scientific view. It considers matter as primary and consciousness as a property of complex material patterns, which emerges at a certain level of biological evolution. Most neuroscientists today subscribe to this view. The other view generally held in mystical traditions. It regards consciousness as the primary reality, as the essence of the universe, the ground of all being, and everything else---all forms of matter and all living beings---as manifestations of that pure consciousness. This mystical view of consciousness is based on the experience of reality in non-ordinary modes of awareness".

The evolution of life having mind and consciousness is, in our view, possible purely due to the ultimate fate of the eternal Absolute ( $\cong$ Void) to express itself through the UM. Without the inherent existence of the universal consciousness, the inanimate matter itself can not generate consciousness which is an inter-linking agent between the inanimate and animate. And further, universal consciousness is a functional state of the UM which is constituted by these TCP and TRP which, in turn, are the ultimate constituents of any matter and any mind in the inherent presence of thought force $\left(\mathrm{T}_{\mathrm{F}}\right)$ in vitro and thought force $\left(\mathrm{T}_{\mathrm{F}}\right)$ in vivo.

It is to be noted that these TCP and TRP are the ultimate constituents of any matter in the inherent presence of thought force $\left(\mathrm{T}_{\mathrm{F}}\right)$ in vitro. And these TCP and TRP are the ultimate constituents of any mind in the inherent presence of thought force $\left(\mathrm{T}_{\mathrm{F}}\right)$ in vivo.

This UM along with the universal consciousness is thus responsible for the manifestation of this Universe with all of its inhabitants. As this UM manifests its own inherent characteristics through the generations of each and all individual minds in a purpose to realize the "reality" of the universe itself, so the biogenesis may be thought to be predetermined. A living organism is thus a complex information processing system and the information is coming from the UM through TCP and TRP.

The Heisenberg's uncertainty principle established that the Void is filled with infinite pairs of virtual particles and antiparticles indicated by Hawking [41]. These pairs would have an infinite amount of energy and therefore, by Einstein's equation: $E=m c^{2}$, they would have an infinite

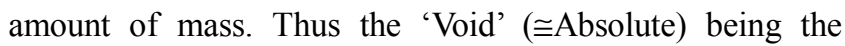
source of infinite energy is the origin of anything and everything in this universe through the presence of universal consciousness. Therefore, the natural physical laws governed by eternal 'Void' (Absolute) cause the evolution of life with consciousness through the generation of DNA and RNA by the quantum mechanical activities of these TCP and TRP which are conceived to be not only the constituents of the $\mathrm{UM}$ but also the ultimate constituents of matter and mind.

Consciousness is an inherent property of the universe; because the universe exists along with the universal consciousness that, in turn, functions as the evolutionary 
force to promote the bio-field.

Pal [5] explained the testability for the existence of TCP and TRP along with the Thought force $\left(\mathrm{T}_{\mathrm{F}}\right)$. Pal [5] mentioned several experimental results to signify the existence of quantum mechanical activities of these TCP and TRP, the ultimate constituents of any matter as well as any mind in the inherent presence of thought force $\left(\mathrm{T}_{\mathrm{F}}\right)$ in vitro and the thought force $\left(\mathrm{T}_{\mathrm{F}}\right)$ in vivo.

\subsection{Conclusion}

Davies [26] in his 'The Fifth Miracle', concluded, "I am of the opinion that there remains a huge gulf in our understanding. It is not merely ignorance about certain technical details; it is a major conceptual lacuna-----we are missing something very fundamental about the whole business---a fully satisfactory theory of the origin of life demands some radically new ideas".

Our consciousness model involving TCP, TRP and thought force $\left(\mathrm{T}_{\mathrm{F}}\right)$ in vitro and thought force $\left(\mathrm{T}_{\mathrm{F}}\right)$ in vivo provides a simple and radically new idea to explain the evolution of universe along with life and consciousness where $\varepsilon_{T}$, the quantized energy of TCP represents universal consciousness.

\section{References}

[1] D. Pal and A.U. De, Physics of consciousness and its model may provide guidelines to solve Many scientific problems. Neuroquantology 1: 17-28(2004)

[2] D. Pal and A.U. De, Consciousness model: Significance of thought-carrying particles and thought-retaining particles in quantum measurement as well as cognitive problem. Neuroquantology 2: 115-116 (2005)

[3] D. Pal and A.U. De, The cosmic microwave background radiation temperature signifying the existence of the thoughtcarrying particle, thought retaining particle and thought force. NeuroQuantology 10: Issue3; 428-442 (September 2012)

[4] M. Bhaumik, Code Name GOD. (Penguin Books India Pvt. Ltd., 11 Community Centre, Panchsheel Park, New Delhi 110 017, India) pp. 132-133; 161-162; 167; 171; 177; 183 and 184. 185-186; 89-190; 198 (2006)

[5] D. Pal, Existence of thought force and its characteristics. Communicated to American Journal of Modern Physics (AJMP) (2013)

[6] V. F. Weisskopf, The Origin of the Universe, The World of Physics, (Simon and Schuster, 1230 Avenue of Americas, New York 10020) 3, pp. 10 and 314 (1987)

[7] D. Pal, Existence of universal consciousness and its characteristics. Accepted for publication in 2014 International Conference on Advanced Education and Management (ICAEM2014) Beijing, China (2013)

[8] S. Vivekananda, The Cosmos (the Microcosm). The complete works of Swami Vivekananda. (Advaita Ashrama, India) 2: pp-212 (1989)

[9] S. Parnia, Do reports of consciousness during cardiac arrest hold the key to discovering the nature of consciousness?
Medical Hypotheses 69(4): 933-937 (2007)

[10] P van. Lommel, R. Wees, V. Meyers and I. Elfferich, NearDeath Experience in Survivors of Cardiac Arrest: A prospective Study in the Netherlands. The Lancet (9298): 2039-45 (2001)

[11] P. Fenwick, S. Parnia, D.G. Waller, and R. Yeates, A qualitative and quantitative study of the incidence, features and aetiology of near-death experiences in cardiac arrest survivors. Resuscitation 48: 149-156 (2001)

[12] M. Beauregard and D. O'Leary, The spiritual brain: A neuroscientist's case for the existence of the soul. (Harper Collins Publishers) (2008)

[13] M. Beauregard and V. Paquette, Neural correlates of a mystical experience in Carmelite nuns. Neuroscience Letters 405, 186-190 (2006)

[14] R. Nelson, Director, Global Consciousness Project, Princeton, New Jersey. (2009) rdnelson@princeton.edu

[15] D. Radin, The Conscious Universe: The Scientific Truth of Psychic Phenomena. (Harper Edge) (1997) ISBN 0-06251502-0.

[16] R. Penrose, Shadows of the Mind: A Search for the Missing Science of Consciousness. (Oxford University Press) (1994)

[17] W. Van De Bogart, Earth portals: Exploring New Metaphors of Consciousness 1993 willard@earthportals.com

[18] P. Davies, How bio-friendly is the universe? International Journal of Astrobiolog 2: 115 (2003)

[19] J.D.Barrow, and F .J. Tipler, The Anthropic Cosmological Principle 318 (1986)

[20] JL. Monod, Chance and Necessity: An Essay on the Natural Philosophy of Modern Biology. (Alfred A. Knopf 1971). ISBN 0-394-46615-2.

[21] I. Prigogine and G. Nicolis, Self-Organization in NonEquilibrium Systems. (Wiley 1977) ISBN 0471024015.

[22] I. Prigogine, From Being To Becoming. (Freeman 1980). ISBN 0716711079.

[23] L. Cosmides and J. Tooby J. From evolution to behavior: Evolutionary psychology as the missing link. (In J. Dupre (Ed.), The latest on the best: Essays on evolution and optimality, Cambridge, MA, The MIT Press. (1987)

[24] L. Cosmides, J. Tooby, J. Barkow, The adapted mind: Evolutionary psychology and the generation of culture. (New York: Oxford University Press. 1992)

[25] L. Cosmides and J. Tooby, Beyond intuition and instinct blindness: Towards an evolutionary rigorous cognitive science. Cognition; 50 (1-3): 41-77 (1994)

[26] P. Davies, The Fifth Miracle: The Search for the Origin and Meaning of Life. (Simon \& Schuster 1999)

[27] E. Wigner, Symmetries and Reflections: Scientific Essays. MIT Press. (1970)

[28] E. Wigner, "Remarks on the Mind-Body Problem", in The Scientist Speculates, I. J. Good, ed. pp. 284-302, Heinemann, London (1961); Basic Books, New York (1962). Reprinted in Wigner $(1967 / 1983)$ 
[29] Vivekananda S. The real and the apparent Man. The complete works of Swami Vivekananda. Advaita Ashrama. (1989)

[30] Takagi Yasuomi, Nucleic Acids Research, , Vol. 29, No. 9; p1815-1834 (2001)

[31] AJ. Levine. The lectin binding and agglutination approach for detecting alterations in transformed cell surfaces induced by SV40 and polyoma. PAABS Revista; 2:289-297 (1973)

[32] AJ. Levine, PC.van der Vliet and JS.Sussenbach. The replication of papovavirus and adenovirus DNA. In Current Topics in Microbiology and Immunology;73:67-124 (1976)

[33] AJ. Levine and JJ.Holland. Mechanisms of viral persistance. Cell; 14:467-472 (1978)

[34] AJ. Levine, SR.Ross and SJ. Flint. Identification of the adenovirus early proteins and their genomic map positions. Virology; 100:419-432. (1980)

[35] Mater John Van Jr. Our Intelligent Companions, the Plants. Sunrise magazine, (April/May 1987)
[36] P. Geddes. The life and work of Sir Jagadis C. Bose, Longmans, Green; 97 (1920)

[37] C. Backster. Primary Perception: Biocommunication with plants, living foods, and human cells. White Rose Millennium Press 2003. ISBN 0-9664354-3-5, Website

[38] HE. Puthoff and R. Fontes. "Organic Biofield Sensor" (1975)

[39] Max. Delbruck. A Physicist's Renewed look at Biology: Twenty years latter. The World of Physics, Simon and Schuster. (1987)

[40] F. Capra. The Tao of Physics. Flemingo, Fontana paperbacks, the Collins Publishing group, 8 Grafton Street, London WIX 3LA; pp. 246 (1990)

[41] SW. Hawking. A Brief History of Time from the Big Bang to Black Holes. Bantam Books, 666 fifth Avenue, New york 10103, pp. 143-144 and 165 (1989) 